\title{
DMA DESIGN \& MODELLING OF URBAN WATER SUPPLY DISTRIBUTION NETWORK IN INDIA
}

\author{
R. L. VIJAYAKUMAR ${ }^{1}$, DR. S. R. KHANDESHWAR ${ }^{2}$ \& ASHISH BHAGAT $^{3}$ \\ ${ }^{1,2}$ Senior Manager, Engineering Services, YCCE, Nagpur, Maharashtra, India
}

${ }^{3}$ Research Scientist, Jawaharlal Nehru Medical College, Datta Meghe Institute of Medical Sciences, Sawangi, Wardha, India

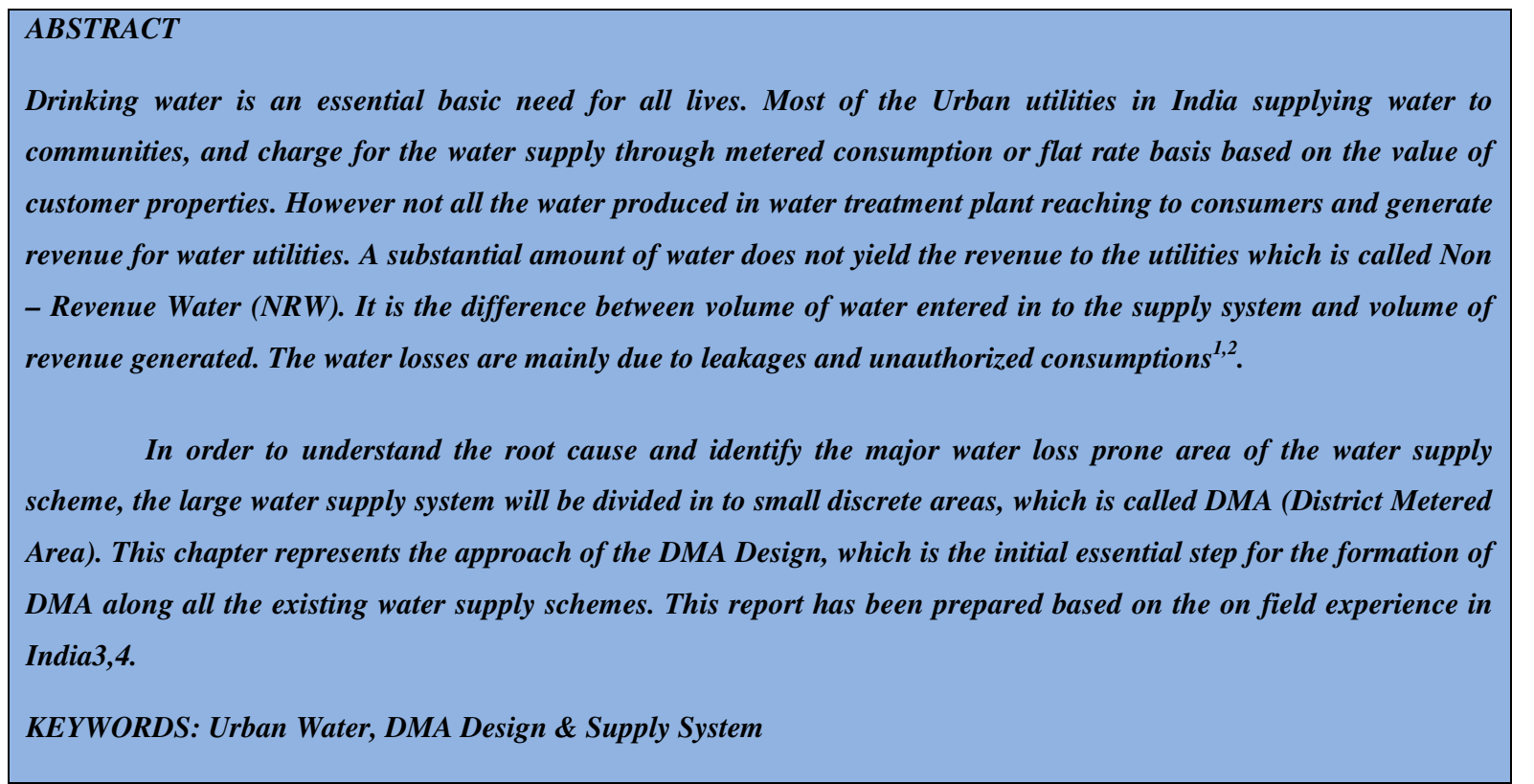

Received: Jun 09, 2020; Accepted: Jun 29, 2020; Published: Aug 11, 2020; Paper Id.: IJMPERDJUN2020718

\section{INTRODUCTION}

The concept of continuously monitoring the behavior vide sub zones or District Metered Area (DMA) in a water supply system is accepted and proven technology worldwide and well established technique for monitoring and identifying areas which contributing more of water losses in the water supply system.

The technique requires setting up of a discrete zone along the water distribution network. DMA must have the boundary with permanently closed boundary valves as boundary will have complete integrity without any pipeline breaches to out of the boundary.

The size of a DMA will vary, universally the DMA contains 1000 to 2500 Nos of house service connections.Ideally DMA will be formed with one inlet equipped with bulk metersbut some cases two or more inflow points equipped with bulk meter based on the ground reality. The creation of DMA concept illustrated in figure:A

Continuously monitoring the DMA behavior allows the engineer to assess the leakage prone area which reduces the awareness time for new leaks. Hence DMA is considered to be the major contributor to cost-effective and leakage management. Also this DMA will lead the utility to derive the economic level of NRW which in terms save huge cost to utility as well as it will act as a decision making platform when and where to take action and 
investing money to reduce the water losses efficiently ${ }^{5,6}$.

In this report we have explained the criteria of DMA design and DMA record plan which is to be maintained by all the utilities in order to understand the characteristics of DMA.

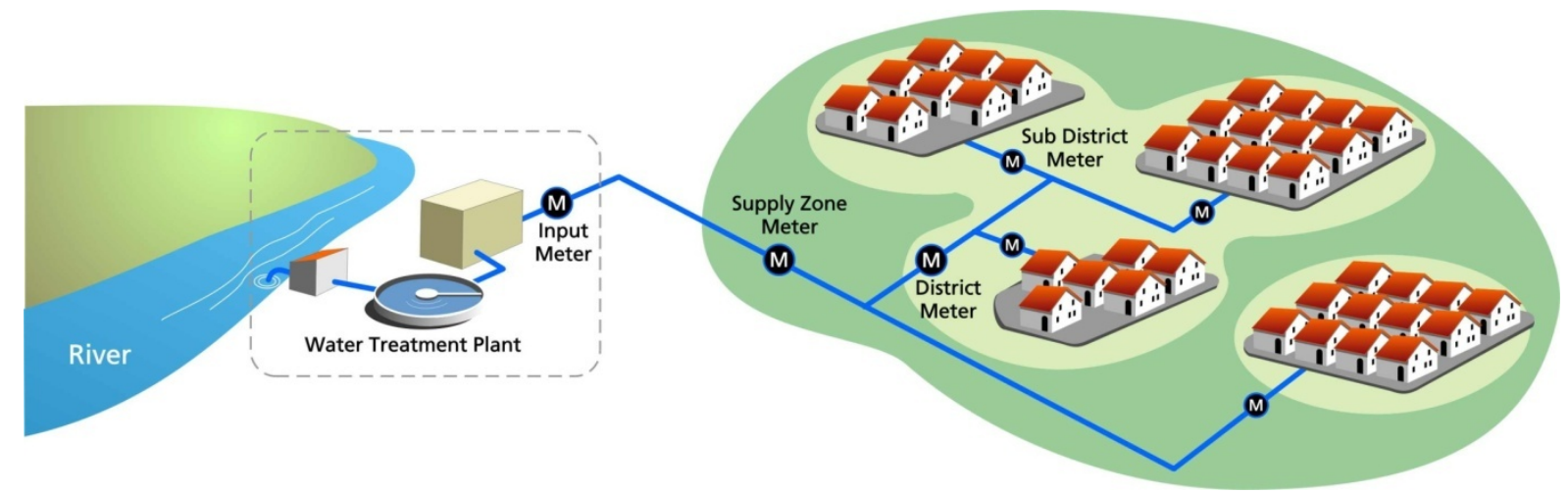

Figure A: DMA Concept.

\section{DMA Design}

The Design of the DMA has been carried out using a set of criteria to create DMA design that has then been tested both in the field and by using a network model. However, the results will be further validated as the network model is calibrated and work progresses.

\section{Criteria of DMA Selection}

- Optimum number of connections in the DMA varies from 1,000 to 2,500 on average. However, based on the actual site conditions and feasibility of hydraulic segregation the number of connections in any particular DMA may vary from 500 to 4,000 connections.

- Minimum number of valves that need to be closed to isolate the DMA

- Optimum number of flow meters to measure inflows and outflows (the fewer meters required, the lower the establishment costs)

- Ground-level variations and thus pressures within the DMA (the flatter the area is more stable the pressures and easier to establish the pressure controls)

- Easily visible topographic features that can serve as boundaries for the DMA, such as canals, drainage channels, railroads, highways, etc.

To divide a large open system into a series of DMAs, it is essential to close valves to isolate a certain area and install flow meters. This process may affect the system pressures, both within that particular DMA as well as its surrounding areas. Therefore, while designing the DMA it is necessary to ensure that the water supply to customers is not compromised in terms of pressure and supply hours ${ }^{7,8,9}$.

\section{Network Modelling for DMA}

Network model is a mathematical approximation of the behavior of the water supply network.It contains information about, 
- $\quad$ Physical location

- Flows

- $\quad$ Pressures

- Demands

The Following data shall be collected each DMA wise as mentioned below,

- DMA Summary, which comprises location of DMA, details of nearest DMA, details of service stations, details of main source

- $\quad$ Property counts of the DMA

- Ground elevation details

- $\quad$ Pipeline diameter and length

- $\quad$ Pipeline Material \& Age

- $\quad$ Metered Consumers Categories

- $\quad$ Details of Large \& Bulk consumers

- Boundary \& Internal valve details

- Inlet to the DMA - Flow measuring points \& details

- Details of public stand post if any

- Water supply Demand \& Future Demand (in case required)

- Consideration of Peak factor based on future demand

- $\quad$ Flow pattern of the DMA (internal valve operation)

- $\quad$ Service to the customer

After Collection of relevant data the DMA design can be carried out using network modelling as illstrated in figure B 


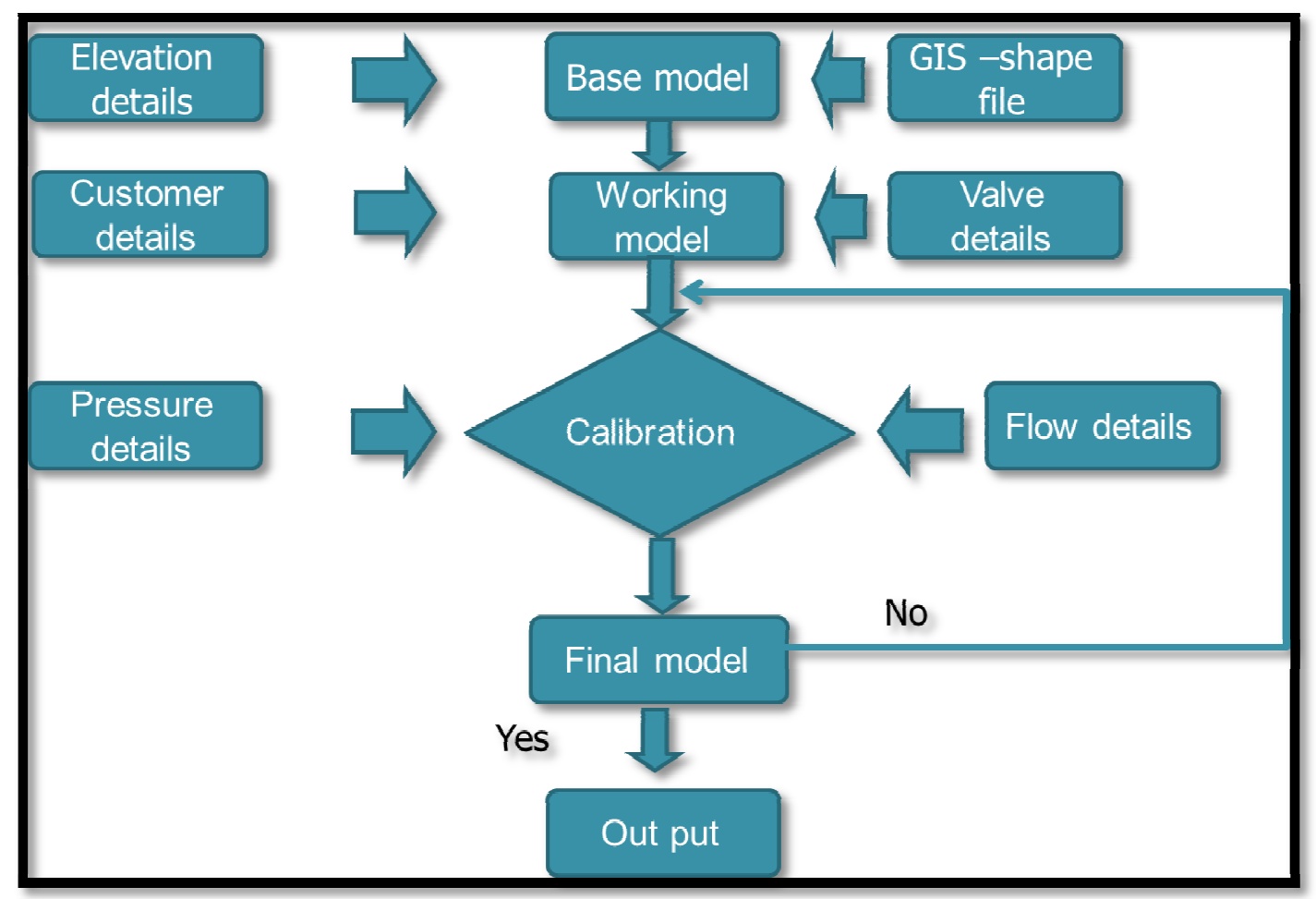

Figure B: DMA Network Model.

\section{Activities Involved in Network Modelling}

- Design criteria based on guidelines of CPHEEO manual.

- Collection of field data as mentioned above.

- Initial level of water balance area wise by conducting temporary flow measurements along DMA inlets.

- Calculate the base demand from the consumption data of the consumers

- $\quad$ Building the model and validate it for the existing water supply network.

- Running the base as well as child scenarios in steady state and extended period simulation mode to check the adequacy of system for continuous water supply.

- $\quad$ Calibrate the base model based on the flow and pressure data from the field and run the model.

- The scenarios for various stages shall include existing water supply network, proposed water supply network, peak demand supply, rehabilitation plan, calibration for existing networks, DMA zone.

- Allocating the demands to the nearest nodes using consumer data for present stage and allocating the demand by creating Thiessen polygon and using load builder with any appropriate method for design stages.

- Checking the demand and supply of the zone including determining the capacity of reservoir using mass curve and rezoning of operational zones.

- Checking the status of reservoir with respect to inflow and outflow of water tanks and representing it graphically for 24 hours. 
- Setting the Flow Control Valves (FCV) for required inflow to the tank, plotting the various profiles with respect to ground level and Hydraulic Grade Level (HGL).

- $\quad$ Provide valve details based on ground reality

- Calibration of hydraulic model to simulate with ground reality shall be done for existing network using field data as per actual observation obtained during water audit.

- Demarcation of various district meter areas (DMAS) showing suitable location of district bulk meter and size of bulk meter.

- Preparing the rehabilitation plan by necessary replacement of pipe and valve etc. using the hydraulic model, running the model.

- Preparation of report, drawing and printing the same in presentation form. Detailed immediate recommendation to rectify the existing water supply network and suggestion to convert the intermittent water supply to continuous water supply stage wise also shall be included in report.

\section{Calibration of Model}

Accurate model= Good decisions.

Next Decision - from model identify:

- $\quad$ Critical Pressure Point (CPP) the point of lowest pressure.

- $\quad$ Average Zone Pressure Point (AZP) - a point which is representative of the average pressure in the DMA.

- Inlet Pressure to understand pressure variations into the DMA

- Calibrate network against current flow/pressure data 


\section{Initial model output $\square$ check site conditions $\longrightarrow$ adjust model variables}

Revised model output $\longrightarrow$ check site conditions $\square$ adjust model variables and so on until satisfied with the result

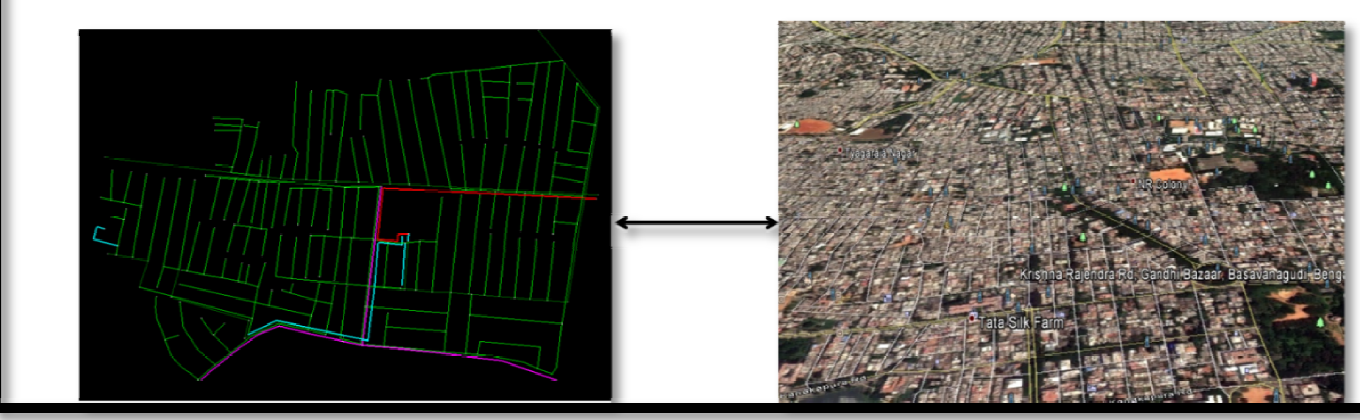

Figure C: Calibration of Model.

\section{CONCLUSIONS}

The activities of Network modelling of District metered area design for the existing system is entirely differs from the green field project. This modelling of DMA initially network model to be carried out based on actual consumption in the area then the model to be calibrated along with flow and pressure data collected from the field ${ }^{10,11,12}$. Once the model become nearby approximation of the actual field then the future projection will be carried out for improvement of the water supply scheme. As mentioned above formation of DMA along the water supply scheme is an essential activity for NRW reduction activities.

\section{REFERENCES}

1. Arunkumar M, NethajiMariappan V. Water demandanalysis of municipal water supply using EPANET. International Journal on Applied Bioengineering. 2011; 5(1)

2. Elsheikh M, Salem $H$ et al. Hydraulic modelling of water supply distributionfor improving its quantity and quality. Sustain. Environ. Res. 2013; 23(6): 403-411.

3. Ramaprasad, N. N., and Priya Narayanan. "Detection of decline in the extent of lakes in Bangalore city using Geospatial techniques." International Journal of Applied and Natural Sciences 4.3 (2014): 9-20.

4. Gupta I, Khitoliya R et al. Studyof water distribution network using EPANET", InternationalJournal of Computational Engineering Research. 2013; 3(6).

5. Ingeduld P., Zdenek S. Modeling intermittent water supply systems with EPANET”, 8th annual WDsymposium EPA Cincinnati 2006.

6. Machell J, Mounce S et al. Onlinemodelling of water distribution systems: a UK case study. Drinking Water Engineering and Science. 2010; 3: 21-27.

7. Ahmed, M. U. S. F. I. Q. U. E., R. I. F. A. T. Anwar, and M. A. Hossain. "Opportunities and limitations in practicing rainwater harvesting systems in Bangladesh." Int J Civil Eng 2.4 (2013): 67-74. 
8. Elsheikh M, Saleh H et al. Hydraulic modelling of water supply distribution forimproving its quantity and quality. Sustain. Environ. Res. 2013; 23(6): 403-411.

9. Mohapatra S, Kamble S et al. Efficiency study of a pilot water distribution systemusing EPANET and ArcGIS10”, Conference CSIR-NEERI 2012.

10. Kumari, S. A. N. G. I. T. A. "Rural-urban migration in India: determinants and factors." International Journal of Humanities and Social Sciences 3.2 (2014): 161-180.

11. Ramesh H., Santhosh L et al. Simulationof hydraulic parameters in water distribution network using EPANET and GIS. International Conference on Ecological, Environmental and Biological Sciences (ICEEBS) 2012.

12. Sumithra R, Mariappan $N$ et al. Feasibility analysis and design of water distribution system for tirunelvelli corporation using Loop and Watergemssoftware. International Journal of Applied Bioengineering. 2013; 7(1).

13. OC, Akakuru, and Akudinobi BEB. "Determination of Water Quality Index and Irrigation Suitability of Groundwater Sources in Parts of Coastal Aquifers of Eastern Niger Delta, Nigeria." International Journal of Applied and Natural Sciences (IJANS) $\operatorname{ISSN}(P)$ (2018): 2319-4014.

14. Cullinane, Lansey M et al. Optimisation availability - based design of water distribution networks. J. Hydraulic engineering, ASCE. 1992; 118(3): 420-441.

15. Gupta R, Bhave P. Reliability Analysis Of Water-Distribution System, J.Environ. Eng. 1994; 120: 447-461.

16. Massou T, Zia A. Dynamic management of water distribution networks based on hydraulic performance analysis of the system. Water science and technology: water supply. IWA. 2003; 3: 95-102. 

